\title{
A ANGÚSTIA E AS FRATURAS SUBJETIVAS DE UMA CLASSE DEGRADADA: O PROLETARIADO PRECARIZADO EM "PASSAGEIRO DO FIM DO DIA", DE RUBENS FIGUEIREDO, E “DE GADOS E HOMENS", DE ANA PAULA MAIA
}

\author{
Rafael Lucas Santos da Silva \\ Submetido em 15 de abril de 2019. \\ Aceito para publicação em 15 de julho de 2019.
}

Cadernos do IL, Porto Alegre, n. ${ }^{\circ}$ 58, outubro. p. 76-93.

\section{POLÍTICA DE DIREITO AUTORAL}

Autores que publicam nesta revista concordam com os seguintes termos:

(a) Os autores mantêm os direitos autorais e concedem à revista o direito de primeira publicação, com o trabalho simultaneamente licenciado sob a Creative Commons Attribution License, permitindo o compartilhamento do trabalho com reconhecimento da autoria do trabalho e publicação inicial nesta revista.

(b) Os autores têm autorização para assumir contratos adicionais separadamente, para distribuição não exclusiva da versão do trabalho publicada nesta revista (ex.: publicar em repositório institucional ou como capítulo de livro), com reconhecimento de autoria e publicação inicial nesta revista.

(c) Os autores têm permissão e são estimulados a publicar e distribuir seu trabalho online (ex.: em repositórios institucionais ou na sua página pessoal) a qualquer ponto antes ou durante o processo editorial, já que isso pode gerar alterações produtivas, bem como aumentar o impacto e a citação do trabalho publicado.

(d) Os autores estão conscientes de que a revista não se responsabiliza pela solicitação ou pelo pagamento de direitos autorais referentes às imagens incorporadas ao artigo. A obtenção de autorização para a publicação de imagens, de autoria do próprio autor do artigo ou de terceiros, é de responsabilidade do autor. Por esta razão, para todos os artigos que contenham imagens, o autor deve ter uma autorização do uso da imagem, sem qualquer ônus financeiro para os Cadernos do IL.

\section{POLÍTICA DE ACESSO LIVRE}

Esta revista oferece acesso livre imediato ao seu conteúdo, seguindo o princípio de que disponibilizar gratuitamente o conhecimento científico ao público proporciona sua democratização.

http://seer.ufrgs.br/cadernosdoil/index

Segunda-feira, 07 de outubro de 2019. 


\title{
A ANGÚSTIA E AS FRATURAS SUBJETIVAS DE UMA CLASSE DEGRADADA: O PROLETARIADO PRECARIZADO EM "PASSAGEIRO DO FIM DO DIA", DE RUBENS FIGUEIREDO, E "DE GADOS E HOMENS", DE ANA PAULA MAIA
}

\author{
THE ANGUISH AND THE SUBJECTIVE FRACTURES \\ OF A DEGRADED CLASS: THE PRECARIOUS \\ PROLETARIAT IN "PASSAGEIRO DO FIM DO DIA", BY \\ RUBENS FIGUEIREDO, AND "DE GADOS E HOMENS", \\ BY ANA PAULA MAIA
}

Rafael Lucas Santos da Silva*

\begin{abstract}
RESUMO: Tendo em vista que o capital financeiro tornou-se fração hegemônica da dinâmica de acumulação capitalista, pretendeu-se neste artigo apreender, na perspectiva da crítica literária dialética, as tensões existentes na relação entre a produção literária brasileira contemporânea e os processos histórico-sociais de precarização do trabalho, com foco no discurso ficcional dos romances Passageiro do fim do dia (2010), de Rubens Figueiredo, e De gados e homens (2013), de Ana Paula Maia. Dessa maneira, para essa análise, o suporte teórico-metodológico utilizado relacionou a estética lukacsiana à abordagem da literatura e processo histórico-social, a partir do qual propõe-se a hipótese de que as narrativas evidenciam e problematizam a dimensão simbólica e subjetiva do processo modernizador autoritário e desigual do Estado brasileiro.
\end{abstract}

PALAVRAS-CHAVE: Literatura brasileira contemporânea; modernização periférica; capitalismo financeiro; precarização do trabalho.

\begin{abstract}
Since financial capital became a hegemonic fraction of the dynamics of capitalist accumulation, it was intended in this article to grasp in the dialectical literary criticism perspective the existing tensions in the relation between contemporary Brazilian literary production and the socialhistorical processes of labor precarization, focusing on the fictional discourse of the novels Passageiro do fim do dia (2010), by Rubens Figueiredo, and De gados e homens (2013), by Ana Paula Maia. Thus, for this analysis, the theoretical-methodological support used related the Lukacsian aesthetic to the approach of the literature and historical-social process, from which it is proposed the hypothesis that the narratives highlight and problematize the symbolic and subjective dimension of authoritarian and unequal modernization process of the Brazilian State.
\end{abstract}

KEYWORDS: Contemporary Brazilian literature; peripheral modernity; financial capitalism; precariousness of work.

\section{Considerações iniciais}

\footnotetext{
* Mestrando na área de Estudos Literários, na Linha de Pesquisa Literatura e Historicidade, pelo Programa de Pós-Graduação em Letras da Universidade Estadual de Maringá - UEM. Possui Graduação em Letras Português/Espanhol e Respectivas Literaturas na Universidade Estadual do Oeste do Paraná UNIOESTE, Campus de Foz do Iguaçu. Contato: i3rafael@ hotmail.com
} 
E foi assim que

Do edifício em construção Que sempre dizia sim Começou a dizer não.

E aprendeu a notar coisas A que não dava atenção: Notou que sua marmita Era o prato do patrão Que sua cerveja preta Era o uísque do patrão

Que seu macacão de zuarte Era o terno do patrão

Que o casebre onde morava Era a mansão do patrão

Que seus dois pés andarilhos Eram as rodas do patrão Que a dureza do seu dia Era a noite do patrão Que sua imensa fadiga Era amiga do patrão. [...]. Vinicius de Moraes (1959)

À primeira vista, dificilmente se poderia cogitar em semelhanças entre os personagens da escritora Ana Paula Maia e do escritor Rubens Figueiredo. Qual seria, afinal, as semelhanças entre Edgar Wilson, assassino e indivíduo brutalizado, e Rosane, idealista e aluna de cursinho de inglês? É possível extrair um denominador comum entre ambos os personagens? Acreditamos que a faísca produzida pelo confronto entre os romances Passageiro do fim do dia e De gados e homens, publicados quase simultaneamente em 2010 e 2013, possa iluminar algo significativo no que tange a políticas conservadoras, desigualdade social e precarização do trabalho da dinâmica socioeconômica brasileira contemporânea.

Jaime Ginzburg (2012) dedicou-se a extrair uma tendência, um ponto de convergência estética sem "reduzir a elevada diversidade de estilos" ao estudar o narrador na literatura brasileira contemporânea; assim, assinalou que a produção literária, a partir do decênio de 1960, constitui-se da presença "recorrente de narradores descentrados" que fazem um contraponto a "um conjunto de campos dominantes na história social" (GINZBURG, 2012, p. 201). Em outras palavras, trata-se de um aspecto que possibilita a representação dos grupos excluídos por meio da voz narrativa, promovendo "desrecalque histórico, de uma atribuição de voz a sujeitos tradicionalmente ignorados ou silenciados" (GINZBURG, 2012, p. 200).

A escolha dos romances Passageiro do fim do dia, de Rubens Figueiredo, e De gados e homens, de Ana Paula Maia, como corpus de análise deste artigo ocorreu em razão de ambos os escritores realizarem esse contraponto à história oficial, conforme argumentado por Ginzburg (2012). Consideramos que a semelhança entre esses dois discursos ficcionais consiste em representar uma fração específica da classe trabalhadora, qual seja, o proletariado precarizado. $\mathrm{Na}$ esteira dos estudos estéticos do filósofo húngaro Georg Lukács (1885-1971), propomos que ambos os romances obtiveram um reflexo estético adequado em relação às tendências essenciais da atual fase do capitalismo, a saber, a lógica da valorização financeira e suas implicações na reestruturação produtiva. 
Embora o fenômeno literário diferencie-se da ciência, ainda assim sua especificidade permite um conhecimento profundo da realidade social:

\begin{abstract}
A literatura pode representar os contrastes, as lutas e os conflitos da vida social tal como eles se manifestam no espírito, na vida do homem real. Portanto, a literatura oferece um campo vasto e significativo para descobrir e investigar a realidade. Na medida em que for verdadeiramente profunda e realista, ela pode fornecer, mesmo ao mais profundo conhecedor das relações sociais, experiências vividas e noções inteiramente novas, inesperadas e importantíssimas (LUKÁCS, 1968, p. 84).
\end{abstract}

Somos levados, assim, a readaptar a sentença do filósofo húngaro aplicada ao romance Ilusões perdidas, de Balzac: "o verdadeiro princípio que, em última análise, determina a unidade do romance é o processo da evolução social. A verdadeira ação do romance consiste na ascensão e no triunfo do capitalismo" (LUKÁCS, 1965, p. 108), no sentido de que a ação dos romances de Rubens Figueiredo e de Ana Paula Maia consiste na ascensão de uma nova morfologia do trabalho sob imposição do triunfo do capitalismo financeiro. Veremos que isso ocorre a partir de um projeto deliberado dos dois escritores cariocas, uma vez que, como argumenta Jameson (1992), compreendemos a narrativa literária "como um ato socialmente simbólico, como a resposta ideológica — embora formal e imanente — a um dilema histórico" (JAMESON, 1992, p. 139). Portanto, a hipótese de leitura explorada neste artigo é que os romances Passageiro do fim do dia e De gados e homens são uma resposta ao dilema histórico-social concernente ao aumento da precarização das condições de trabalho e existenciais das classes subalternas, que foi produzida a partir dos decênios de 1990 e 2000 com a regulação neoliberal.

\title{
2 Desiguais porém combinados
}

Desde os anos 2000, os escritores Rubens Figueiredo e Ana Paula Maia vêm construindo uma sólida e coerente obra ficcional. Já alcançaram extrema relevância no cenário contemporâneo de produção literária, com ampla divulgação internacional, e conquistaram prêmios de importantes concursos literários. Contudo, é a partir de 2009/2010 que esses escritores buscam aprofundar a elaboração de uma crítica social ao contexto político-econômico brasileiro, que nos remete ao argumento de Lukács (1965), segundo o qual

\footnotetext{
O escritor precisa ter uma concepção do mundo inteiriça e amadurecida, precisa ver o mundo na sua contraditoriedade móvel, para selecionar como protagonista um ser humano em cujo destino se cruzem os contrários (...) $\mathrm{Na}$ verdade, quanto mais uma concepção do mundo é profunda, diferenciada, nutrida de experiências concretas, tanto mais plurifacetada pode se tornar a sua expressão compositiva. (LUKÁCS, 1965, 83).
}

Assim, o filósofo húngaro considera fundamental que a forma literária exponha as complexas conexões entre a superfície imediata e a dinâmica histórica profunda movida pelas relações de classe. É nesse sentido que compreendemos a guinada artística de Rubens Figueiredo e Ana Paula Maia. Vejamos: 
Ivone Daré Rabello (2007) produziu uma importante leitura que visou demonstrar que é possível conceber duas fases do escritor, dado não haver entre o romance Barco a seco, publicado em 2001, e os romances anteriores "nenhuma continuidade estilística ou temática" (RABELLO, 2007, p. 129), de modo que acredita ser o aspecto fulcral dessa transformação "não a experimentação com os gêneros, e sim a matéria a formalizar nas obras, bem como os resultados da composição e do estilo" (RABELLO, 2007, p. 129, grifo da autora).

Compreendemos que esse argumento de Rabello (2007) põe em jogo a necessidade de verificar como, nessa segunda fase, o escritor Rubens Figueiredo formaliza esteticamente fatores histórico-sociais. A esse respeito, vale lembrar uma entrevista do escritor carioca, na qual declarou que "[...] no ano 2000 eu publiquei um livro chamado Barco a seco [...] tentando elaborar um tipo de questionamento sobre a ordem social, mas havia certa timidez" (FIGUEIREDO, 2011, p. 192).

Acreditamos que, de fato, o romance Passageiro do Fim do dia apresenta uma decisiva inflexão no processo autoral de Rubens Figueiredo, apenas timidamente articulado no romance anterior conforme exposto por Rabello (2007), no que corresponde à formalização estética diante de fatores histórico-sociais. O escritor, em sua experiência como professor da rede estadual com alunos trabalhadores do período noturno, percebeu que

\begin{abstract}
a questão é que tudo o que há de desumanizador na sociedade vai para lá - ali é o grau máximo. Nas classes trabalhadoras, pobres, lá é que o processo desumanizador é mais completo. Essa massa é que tem que ficar acachapada, no fundo. Tem que ficar. Então, o discurso não costuma ser de indignação. Às vezes até é, mas o que eu sentia mais era um discurso de resistência, de procurar estratégias para sobreviver, uma maneira de escapar (FIGUEIREDO, 2011, p. 203).
\end{abstract}

Dessa maneira, Rubens Figueiredo decidiu privilegiar a representação da classe trabalhadora em Passageiro do fim do dia, assim como Ana Paula Maia; por exemplo, na obra Entre Rinhas de Cachorros e Porcos Abatidos, a escritora esclarece no prefácio que

\begin{abstract}
este livro reúne duas novelas literárias compostas de homens-bestas, que trabalham duro, sobrevivem com muito pouco, esperam o mínimo da vida e, em silêncio, carregam seus fardos e o dos outros. [...] retratam a amarga vida de homens que abatem porcos, recolhem o lixo, desentopem esgoto e quebram asfalto. Toda imundície de trabalho que nenhum de nós quer fazer, eles fazem, e sobrevivem disso (MAIA, 2011, s/p, grifo nosso).
\end{abstract}

Da mesma forma como aqui é ressaltado o fardo do trabalho dos personagens, por sua vez, em De gados e homens, quarto romance de Ana Paula Maia, publicado em 2013, deparamo-nos com a dinâmica produtiva de um matadouro, no qual Edgar Wilson está submetido a uma rotina precarizada, em que "por dia precisa matar mais de cem vacas e bois e trabalha seis dias por semana, folgando apenas no domingo" (MAIA, 2013, p. 19).

Com efeito, percebe-se a intenção de Ana Paula Maia em elaborar representações de uma fração específica da classe trabalhadora, os "homens-bestas", como Edgar Wilson, que compõem uma classe subalterna vítima da precariedade que os 
tornam subcidadãos desprovidos de capital cultural e econômico em qualquer medida significativa.

Portanto, a rigor, apesar das diferenças estilísticas dos dois escritores cariocas, é possível depreender um projeto literário de realizar críticas sociais ao modo como é tratada a classe trabalhadora. Em ambos os romances, a conduta discricionária dos narradores está modulada pela instância de enunciação em terceira pessoa e o trabalho é a temática fundamental que amalgama a existência e o conteúdo mental de seus personagens. Em Passageiro do fim do dia, embora Pedro seja o protagonista, o foco narrativo incide sobre outros personagens relacionados à sua namorada Rosane, cujas biografias são fraturadas pela exploração e precarização do trabalho; mesma fratura que desfigura a biografia de Edgar Wilson, pois em De gados e homens, desenvolve-se uma história cujas ações se passam na fazenda "Touro do Milo", centrada nesse personagem que pertence à camada da população excluída do acesso a políticas socioeconômicas, sobrevivendo em uma brutalidade abjeta de um cotidiano cruel.

Depreende-se, assim, narrativas que dão ênfase à espoliação e exploração da classe trabalhadora, aspecto substancial para Žižek (2012), uma vez que esse filósofo considera a dinâmica da exploração do trabalho como demonstrativa do caráter estrutural do problema e direciona a crítica ao modo de produção capitalista, diferentemente de uma perspectiva voltada para a distribuição de poder político e formas de participação no Estado, característica das posições pós-modernas e que tende a supervalorizar uma perspectiva regulatória, vinculada ao critério da democracia:

\begin{abstract}
A importância dessa ênfase na exploração torna-se clara quando a contrapomos à dominação, tema predileto das diferentes versões da "micropolítica do poder" pós-moderna. Em suma, Foucault e Agamben não são suficientes: todas as elaborações detalhadas dos mecanismos de regulação do poder da dominação, toda a riqueza de conceitos, como excluídos, vida nua, homo sacer etc., devem ser fundamentadas na (ou mediadas pela) centralidade da exploração; sem essa referência à economia, a luta contra a dominação permanece "uma luta essencialmente moral ou ética, que leva a revoltas pontuais e atos de resistência, e não à transformação do modo de produção enquanto tal" - o programa positivo das ideologias do "poder" é em geral o programa de determinado tipo de democracia "direta". O resultado da ênfase na dominação é um programa democrático, ao passo que o resultado da ênfase na exploração é um programa comunista (ŽIŽEK, 2012, p. 18).
\end{abstract}

Em conformidade com o filósofo esloveno, é fundamental não perder de vista a questão econômica e sua implicação para a classe trabalhadora. Por isso, é necessário compreender as mudanças econômicas e suas implicações histórico-sociais, antes de fazermos uma leitura mais detalhada dos romances em questão.

Nesse aspecto, Harvey (2008) nos ajuda a compreender que, a partir de meados do decênio de 1970, a fase atual do capitalismo global, com sua lógica da valorização financeira, precisou romper a rigidez do que comumente era nominado como "fordismo", para suceder, assim, a aceleração da circulação do capital monetário, de maneira que, por conseguinte, essa lógica da valorização financeira

[...] é marcada por um confronto direto com a rigidez do fordismo. Ela se apoia na flexibilidade dos processos de trabalho, dos mercados de trabalho, dos produtos e padrões de consumo. Caracteriza-se pelo surgimento de setores de produção inteiramente novos, novas maneiras de fornecimento financeiros, novos mercados e, sobretudo, taxas altamente intensificadas de 
Compreende-se, assim, que essa lógica do capital financeiro afeta diretamente a produção e, via de consequência, a classe trabalhadora, ao privilegiar focos de acumulação flexível, que provoca "uma radical reestruturação" do mercado de trabalho que implica níveis relativamente altos de "desemprego 'estrutural' (em oposição a 'friccional'), [...] ganhos modestos (quando há) de salários reais e o retrocesso do poder sindical - uma das colunas políticas do regime fordista" (HARVEY, 2008, p. 141142).

A economista Paulani (2008) pontua que a dinâmica socioeconômica brasileira está, evidentemente, alinhada com esse processo atual do capital financeiro global, desde os anos 1980 quando, de forma passiva, foi vítima da chamada "crise da dívida externa", depois de forma ativa, quando tomou providências, a partir de meados dos anos 1990, para seu ingresso na era da financeirização como "potência financeira emergente". Conforme a autora, trata-se de um sistema perverso, visto que engordar o capital financeiro implica diminuir o capital produtivo:

[...] dada essa lógica [...] o equilíbrio financeiro [...] está na dependência de um comportamento das variáveis macroeconômicas-chave que é perverso do ponto de vista do crescimento e do emprego, pois joga no sentido da elevação dos juros básicos, da redução da mão-de-obra formalmente empregada e da queda do rendimento médio dos trabalhadores (PAULANI, 2008, p. 98-99).

No bojo dessa conjectura econômica, o decênio de 1990 foi, então, o início de um período de aumento da exploração de trabalho que fez "a precarização do trabalho afirmar-se no século XXI como precarização estrutural do trabalho" (ALVES, 2013, p. 48).

Compreende-se, assim, que o desenvolvimento do modo de produção capitalistaindustrial ocorre através de intensos processos de reestruturação produtiva, de modo que as dimensões específicas da precarização do trabalho no século XXI precisam ser concebidas como processo social de conteúdo histórico-político que atinge a classe trabalhadora brasileira. Alves (2007) delineia de forma esclarecedora quais são os aspectos desse processo social:

\begin{abstract}
A precarização é um atributo modal da precariedade. É uma forma de ser sócio-histórica da condição ontológica da força de trabalho como mercadoria. Enquanto existir precariedade haverá possibilidade objetiva de precarização que pode assumir dimensões objetivas e subjetivas. A precarização não apenas desvela uma condição ontológica da força de trabalho como mercadoria, mas explicita novos modos de alienação/estranhamento e fetichismo da mercadoria no mundo social do capital (ALVES, 2007, p. 115).
\end{abstract}

Tendo tudo isso em vista, pretende-se agora demonstrar como a precariedade é a condição ontológica do ser social dos personagens Rosane e Edgar Wilson.

\title{
3 Rosane e Edgar Wilson, proletários precarizados?
}

Consideramos importante ter uma compreensão preliminar da reestruturação capitalista na dinâmica socioeconômica brasileira, porque concordamos com Lukács 
(2009) que "a lei geral da desigualdade entre o desenvolvimento espiritual e o progresso material, estabelecida por Marx, manifesta-se claramente também no destino da teoria do romance" (LUKÁCS, 2009, p. 193). Ou seja, o crescimento financeiro e material global, que possibilitou o aumento de consumo nos estratos sociais menos favorecidos, foi o berço de origem de Rosane e Edgar Wilson. Neste, o caráter brutalizado é semelhante a um cão de rinha:

Cão de rinha é um cão que não teve escolha. Ele aprendeu desde pequeno o
que o seu dono ensinou. Podem ser reconhecidos pelas orelhas curtas ou
amputadas e pelas cicatrizes, pontos e lacerações. Não tiveram escolhas.
Exatamente como Edgar Wilson [...] criado feito cão de rinha (MAIA, 2011,
p. 46).

Esse é, pois, o aspecto identitário de Edgar Wilson, sujeito fraturado, com diversas cicatrizes ocasionadas não por rinhas com outros seres humanos, mas sim pela violência sistêmica do processo modernizador autoritário e desigual do Estado brasileiro. Por sua vez, Rosane esteve em empregos precarizados, que inclusive lhe provocaram lesões corporais. Vinda do campo, Rosane idealiza possibilidades de ascender socialmente. Em ambos os romances, existe um nexo entre as subjetividades e a condição de classe, levando-nos a compreender e classificar Rosane e Edgar Wilson como proletários precarizados, conforme as reflexões sociológicas de Ruy Braga (2012).

Conforme Braga (2012), o proletariado precarizado diferencia-se do grupo mais qualificado e estável da classe trabalhadora, pois pertence à "fração mais mal paga e explorada do proletariado urbano e dos trabalhadores agrícolas" (BRAGA, 2012, p. 21). Com essa concepção, o sociólogo argumenta que o proletariado precarizado se encontra "no coração do próprio modo de produção capitalista e não como subproduto da crise do modo de desenvolvimento fordista" (BRAGA, 2012, p. 22, grifo do autor). Nesse sentido, compreende-se os trabalhadores precarizados como uma fração da classe trabalhadora em permanente trânsito entre a possibilidade da exclusão socioeconômica e o aprofundamento da exploração econômica. Aqui, devemos lembrar que, segundo o discurso narrativo e a perspectivação dos acontecimentos diegéticos dos romances, Rosane e Edgar estão nesse trânsito, já que trabalharam em diferentes empregos num curto período de tempo. Sempre é destacado pelas narrativas como a dinâmica produtiva desses empregos incide profundamente em suas subjetividades, a partir de modalidades de angústia psíquica. Citando Marx, o autor de A política do precariado esclarece as implicações nefastas que atingem tanto Rosane na fábrica de copos de suco quanto Edgar no matadouro em relação ao aumento de produção:

[...] Quanto maior a produtividade do trabalho, tanto maior a pressão dos trabalhadores sobre os meios de emprego, tanto mais precária, portanto, sua condição de existência, a saber, a venda da própria força de trabalho para aumentar a riqueza alheia ou a expansão do capital (MARX apud BRAGA, 2012, p. 22)

Pode-se compreender, assim, que, no interior do discurso narrativo de ambos os romances, emerge uma crítica a um processo de naturalização da desigualdade e da exploração social, que leva os personagens a formas perversas de subcidadania e marginalização. 


\subsection{Rosane}

Rosane é namorada de Pedro, protagonista do romance Passageiro do fim do dia. Embora Pedro seja o protagonista, o foco narrativo incide sobre outros personagens relacionados à sua namorada Rosane, cujas biografias são fraturadas pela exploração e precarização do trabalho.

Rosane reside em um bairro periférico da cidade, nominado Tirol, que possui "ruas poeirentas" com "antigas tubulações de esgoto e as fossas de vinte anos antes [que] já não davam vazão", de maneira tal que "os dejetos às vezes corriam em canaletas descobertas ou onde encontrassem passagem" (FIGUEIREDO, 2010, p. 3637). Ela precisa se locomover mais de quarenta quilômetros até o centro da cidade para poder trabalhar em condições subalternas. E isto ainda é concebido como um privilégio, uma espécie de bênção, porque a maioria de suas amigas e amigos de infância estão ou desempregados ou presos ou mortos. Conforme ela relata, havia vizinhos que nunca foram ao centro da cidade e, assim, "algumas de suas amigas nunca tinham ido a nenhum bairro a mais de dez quilômetros de distância" (FIGUEIREDO, 2010, p. 52). Em outro relato seu ao namorado Pedro, Rosane diz que "depois de frequentar a escola durante alguns anos, algumas delas mal sabiam ler, trocavam letras, paravam no meio. Encaravam as palavras e as contas com hostilidade" (FIGUEIREDO, 2010, p. 59).

Outros exemplos são trazidos à baila a partir da própria relação que Rosane mantém com diferentes personagens, em proliferação de episódios intercalados. Um desses episódios traz os próprios pais de Rosane, constantemente abusados pelos patrões. Primeiramente é exposto que seus pais foram caseiros em um sítio cujo proprietário "não lhes pagava um salário fixo", de modo que tinham que plantar para ter o que comer, e quando o dono chegava "se julgava no direito de levar o que tivessem produzido" (FIGUEIREDO, 2010, p. 32). Em seguida, o pai de Rosane trabalhou em uma firma que fechava e reabria de dois em dois anos com outro nome, "para não ter de pagar os direitos trabalhistas aos empregados e poder fugir de impostos" (FIGUEIREDO, 2010, p. 57). Ele também trabalhou em obras sem receber a proteção necessária: "de tanto trabalhar descalço, sem luvas, ele pegou uma alergia ao cimento cru" (FIGUEIREDO, p. 100). Os amigos do pai de Rosane também estavam desempregados:

\footnotetext{
[...] no máximo arranjavam trabalhos clandestinos, e por um tempo curto, em que ganhavam ainda menos. Naqueles serviços, não tinham hora para ir para casa, os pagamentos atrasavam semanas, meses até. Várias vezes levavam calotes do patrão e no fim não recebiam nada. $\mathrm{O}$ dono da obra sumia, o escritório fechava de repente, eles nem tinham de quem cobrar (FIGUEIREDO, 2010, p. 117).
}

Consideramos importante notar que, durante o discurso narrativo, propagandas publicitárias da tv são constantes. Muitos relatos de Rosane são feitos a Pedro em frente da televisão, cujas publicidades captam as atenções. Elas atingem Rosane e Pedro, desencadeando uma economia libidinal característica do fetichismo da mercadoria, no sentido em que esta é um "gozo de imagens, gozo de uma imaginação que procura reduzir os objetos a imagens fantasmáticas de satisfação" (SAFATLE, 2010, p. 44). Esse tipo de fetiche da mercadoria está constantemente bombardeando Pedro e Rosane, quando estão juntos assistindo televisão: 
Na tevê à frente deles, o anúncio de um banco mostrou um casal risonho, de roupas bem passadas, com cartões de plástico coloridos na ponta dos dedos: os dois cartões se tocavam e, com uma faísca prateada que saltava, parecia que os cartões se beijavam no ar. De repente, uma mangueira esguichava em leque por cima de um gramado. Um carro encostava diante da casa recémpintada. A lataria espelhava o azul do céu. Uma porta do carro abria, uma criança saltava para fora e corria sobre a grama. A tela inteira era tomada pela cabeça e pelo tronco de uma jovem no impulso de sair de uma piscina, enquanto a pele bronzeada gotejava. Os quinze segundos do anúncio se arrastavam, não queriam passar. Tentavam congelar-se, ficar em suspenso, encher a sala e a casa, enquanto Pedro e Rosane, sem perceber, aguardavam mudos, atentos à promessa de um sinal, de uma autorização, para que também eles se integrassem àquela visão (FIGUEIREDO, 2010, 54-55).

Do ponto de vista do capital financeiro, essa cena torna-se muito importante, visto que Alves (2013) considera que, na fase atual do capitalismo, ampliou-se e intensificou-se "a produção de fetichismos sociais, agudizando a alienação e o estranhamento de homens e mulheres que trabalham" (ALVES, 2013, p. 39). Conforme é exposto por Alves (2013), na "era do capital financeiro" ocorre uma "corrosão da capacidade subjetiva", "na medida em que não se afirma como ser-para-si-mesmo tornase ser-para-outrem, o Outro estranho e abstrato e fetichizado (o capital)" (ALVES, 2013 p. 116-117).

Ainda em conformidade com a argumentação de Alves (2013), essa condição que surge da alienação do trabalho e do fetiche da mercadoria é vivenciada de forma mais intensa nos estratos precarizados da força de trabalho.

No discurso narrativo do romance, são expostos dois trabalhos de Rosane: o primeiro em "uma fábrica de copinhos de mate" (FIGUEIREDO, 2010, p. 152), na qual

[...] de salário, com os descontos normais, ela quase que só ganhava o bastante para pegar o ônibus e comer. Não tinha horário fixo, era obrigada a fazer horas-extras a qualquer momento e sem a remuneração devida por isso, havia mudanças de turno a toda hora e sem aviso, e por isso ela teve de largar o colégio: seus dias, mal nasciam, eram tomados um a um, em troca de quase nada. Além do mais, um cheiro constante de xarope ou de óleo engrossava o ar dentro do galpão, se acumulava aos poucos no fundo do estômago num enjoo constante. Isso para não falar no barulho: ela chegava em casa com a cabeça num tal estado que tinha de ficar de olhos fechados durante quase meia hora, de cara metida no travesseiro. Nem ver televisão ela aguentava (FIGUEIREDO, 2010, p. 158).

Pior do que isso, ocorreu ainda de Rosane ter lesionado o pulso devido ao movimento repetitivo na fábrica, provocando-lhe uma dor aguda, impossibilitando-a até mesmo de tocar o pulso com o dedo. A intensa dor fez com que fosse ao departamento médico da fábrica:

A médica da fábrica, afobada para ir embora - e isso pouco depois de ter chegado - a médica deu a ela um dia de dispensa. No dia seguinte, diante da esteira de metal em movimento, Rosane mal tentou segurar um copinho de plástico e logo ele caiu da sua mão. Soltou um grito curto, chorou sem barulho, o pulso encolhido no meio do peito, os ombros curvados para a frente. Preso dentro da boca, um outro gemido subiu e demorou a terminar (FIGUEIREDO, 2010, p. 155). 
O baixo salário recebido por Rosane corresponde à atual desconstrução dos direitos trabalhistas, que fez surgir "o que podemos considerar um salariato precário, decorrente da precarização intensa das condições de contratação salarial do proletariado" (ALVES, 2007, 91). Novamente, bem compreendidas, essas cenas evidenciam a violência sistêmico-simbólica do capital financeiro, que atinge a classe trabalhadora, precarizando-a, conforme atesta a segunda experiência de trabalho de Rosane em um escritório de advocacia:

\footnotetext{
Era copeira, fazia faxina, mas também atendia telefones, ficava na recepção e, quando pediam, fazia até alguns serviços no computador, pois tinha frequentado um curso gratuito e sabia mexer nos principais programas. $[\ldots]$

Pagavam o salário mais baixo possível, descontado de todas as formas possíveis, como sempre acontecia. E às vezes pediam para trabalhar fora do horário, sem nunca pagar hora-extra, como também sempre acontecia. Mesmo assim, ali, como em toda parte, achavam que já estavam pagando muito, que a despesa era excessiva, que os impostos eram altos, que as pessoas não sabiam economizar, que uma empresa moderna tinha de ter poucos empregados ganhando o mínimo possível. Mas, no fim das contas, davam vale-transporte, tíquete-refeição, carteira assinada, férias, décimo terceiro salário - e pagavam em dia. (FIGUEIREDO, 2010, p. 45; 60).
}

Esse escritório de advocacia está fortemente adequado ao discurso neoliberal, submetendo o trabalho às condições de precarização, resultantes do processo de reestruturação produtiva, que ainda visa à precarização dos direitos sociais do trabalho. Conforme explica Alves (2007, p. 112), "uma das determinações estruturais do modo de produção e reprodução capitalista é a constituição sistêmica, a partir de processos de precarização do trabalho vivo, de formas históricas de precariedade social", de tal forma que é possível conceber a manifestação da precariedade sistêmico-simbólica durante todo o discurso narrativo de Passageiro do fim do dia.

\subsection{Edgar Wilson}

Edgar Wilson vive no alojamento da fazenda "Touro do Milo" com outros cinco trabalhadores (Bronco Gil, Helmuth, Emetério, Burunga e Zeca). Nessa fazenda, funciona um matadouro de bovinos que fornece carne para uma fábrica de hambúrguer; todos esses personagens trabalham nele, sendo que Edgar Wilson tem a função de atordoar o gado com um intenso golpe de marreta, para que durante o seu desnorteamento a sua garganta seja cortada. Conforme indica o discurso narrativo, Edgar Wilson "não sente orgulho do trabalho que executa, mas se alguém deve fazê-lo que seja ele, que tem piedade dos irracionais" (MAIA, 2013, p. 15).

O discurso narrativo principia com a descrição submissa de Edgar Wilson, que está próximo da entrada do escritório de Seu Milo, o proprietário da fazenda e do matadouro, que o havia chamado para lhe dar uma ordem:

Edgar Wilson está apoiado no batente da porta do escritório do seu patrão, o fazendeiro Milo, que conclui um telefonema aos berros, já que desde cedo aprendeu a berrar, quando solto no pasto, ainda bem menino, disputava com o bezerro a teta da vaca. $\mathrm{O}$ escritório não passa de um cômodo espremido ao 
lado do setor de bucharia do matadouro.

- O senhor queria falar comigo?

- Quero sim, Edgar.

— Pois não - diz Edgar Wilson, que tira o boné da cabeça e segura-o contra o peito respeitosamente ao entrar no escritório.

- Preciso que você vá até a fábrica de hambúrguer fazer uma cobrança (MAIA, 2013, p. 9).

Em face da ordem, a primeira reação de Edgar Wilson foi a de protestar por ter que fazer essa atividade que não faz parte de sua atribuição dentro da divisão de trabalho no matadouro. Percebe-se com isso a flexibilização da força de trabalho acarretada pela lógica do capital financeiro, que contribui para o aumento da precarização do trabalho de Edgar Wilson; flexibiliza-se, pois, não há mais a rigidez do fordismo, que prezava pela fragmentação das funções (HARVEY, 2008). De fato, ao longo do discurso narrativo, é exposto que Edgar Wilson tem uma jornada de trabalho de mais de doze horas, que faz horas extras sem receber, que recebe um salário precário. Essa é nova morfologia do trabalho, reestruturada a partir do capital financeiro, denominada por Alves (2007) e Antunes (2000) como "toyotismo", cuja racionalização preza pela

[...] efetiva flexibilização do aparato produtivo, [a qual] é também imprescindível a flexibilização dos trabalhadores. Direitos flexíveis, de modo a dispor desta força de trabalho em função direta das necessidades do mercado consumidor. O toyotismo estrutura-se a partir de um número mínimo de trabalhadores, ampliando-os, através de horas extras, trabalhadores temporários ou subcontratação, dependendo das condições de mercado (ANTUNES, 2000, p. 36).

Esse dado é importante, pois no encadeamento da cena supracitada Seu Milo concede uma importante resposta: "Meu pessoal tá curto, Edgar" (MAIA, 2013, p. 10), a partir da qual podemos perceber que o matadouro se estrutura com o mínimo de trabalhadores. Assim, a conclusão da cena é o obedecimento por parte de Edgar, que antes de ir ao frigorífico passa no seu setor de trabalho, narrado de forma desoladora:

Edgar Wilson permanece em silêncio enquanto aguarda a decisão do patrão. [...] Também não é costume de Edgar Wilson deixar de cumprir o que pedem. $\mathrm{O}$ telefone toca. Milo atende e pede um instante.

- Edgar, aqui está a ordem de cobrança. O endereço tá escrito aí. Pega as chaves da caminhonete com o Tonho e manda o Zeca vir até aqui falar comigo.

Edgar Wilson acena com a cabeça e apanha a ordem de cobrança. Milo volta ao telefone. Edgar hesita pouco antes de sair, mas atravessa a porta do escritório e fecha-a ao passar. Segue por um corredor fétido e mal iluminado e ao virar à direita entra no boxe de atordoamento, local em que trabalha muitas horas por dia. A fila de bois e vacas é sempre longa. Um funcionário abre a portinhola e o boi que já passou pela inspeção e pelo banho entra devagar, desconfiado, olhando ao redor. Edgar apanha a marreta. O boi caminha até bem perto dele. Edgar olha nos olhos do animal e acaricia a sua fronte. O boi bate uma das patas, abana o rabo e bufa. Edgar cicia e o animal abranda seus movimentos. Há algo nesse cicio que deixa o gado sonolento, intimamente ligado a Edgar Wilson, e dessa forma estabelecem confiança mútua. Com o polegar lambuzado de cal, faz o sinal da cruz entre os olhos do ruminante e se afasta dois passos para trás. É o seu ritual como atordoador. Suspende a marreta e acerta a fronte com precisão, provocando um desmaio 
causado por uma hemorragia cerebral. O boi caído no chão sofre de breves espasmos até se aquietar. Não haverá sofrimento, ele acredita (MAIA, 2013, p. 11-12).

Nós, leitores, podemos vivenciar essa cena, sentir as horas pútridas que Edgar permanece realizando um trabalho que avilta suas capacidades singulares subjetivas, por permanecer mais de doze horas diárias "diante de bois e vacas pendurados de cabeça para baixo pelas patas traseiras e com os pescoços cortados jorrando litros de sangue em tonéis fétidos, misturado a vômito e outros excrementos" (MAIA, 2013, p. 78). Acreditamos, assim, que essas cenas já exprimem a contradição da lógica do capital financeiro, a qual, pela reestruturação produtiva, favorece a subjugação dos sujeitos a situações de impossibilidade afetiva, emocional, moral e existencial.

Nisto, observa-se como o discurso narrativo em De gados e homens está de acordo com o fato assinalado por Lukács (1965), a respeito do realismo, de que "a verdade do processo social é também a verdade dos destinos individuais" (LUKÁCS, 1965, p. 57). Essa conexão entre personagem e processo social fica ainda mais evidente com o encadeamento das cenas da ida de Edgar Wilson ao frigorífico, nas quais o narrador focaliza a exploração da força de trabalho de Edgar Wilson e a sua relação com o produto final de seu trabalho:

\begin{abstract}
Após apanhar as chaves com Tonho, segue até a caminhonete e lamenta o rádio quebrado do carro. Desde que abandonou o trabalho nas minas de carvão, tudo o que conseguiu foi trabalhar com gado [...]. Depois de esquartejados, são enviados para duas fábricas de hambúrguer e distribuídos para alguns frigoríficos, que mandam caminhões buscar os lotes de carne. Edgar Wilson nunca comeu um hambúrguer, mas sabe que a carne é moída prensada e achatada em formato de disco. Depois de frita, é colocada entre duas fatias de pão redondo recheado com folhas de alface, tomate e molho. $\mathrm{O}$ preço de um hambúrguer equivale a dez vacas abatidas por Edgar, já que recebe centavos por cada animal que derruba. Por dia precisa matar mais de cem vacas e bois e trabalha seis dias na semana, folgando apenas no domingo (MAIA, 2013, p. 18-19, grifo nosso).
\end{abstract}

Tal aspecto poderia render longa reflexão econômico-política, visto que a condição de Edgar Wilson é tão miserável que não lhe permite acesso ao próprio produto final de seu trabalho. É importante notar que Edgar Wilson não é vegetariano ou vegano, de modo que o fato de ele nunca ter comido um hambúrguer demonstra a factualidade alienada e alienante de seu trabalho, que faz as mercadorias serem mais valorizadas do que o ser humano. Por ser uma situação grave e enfática, cumpre lembrar, ainda que brevemente, uma conclusão de Marx (2004) a partir de sua investigação sobre as relações mercantis e as determinações ontológicas e históricas advindas das relações de trabalho. Assim, nos Manuscritos econômico-filosóficos, de 1844, Marx (2004) expôs que, na sociedade burguesa, o trabalhador se torna objeto, sendo empobrecido econômica e subjetivamente:

[...] o trabalhador se torna uma mercadoria tão mais barata quanto mais mercadorias cria. Com a valorização do mundo das coisas (Sachenwelt) aumenta em proporção direta a desvalorização do mundo dos homens (Menschenwelt). A apropriação do objeto aparece em tal medida como alienação que quanto mais objetos produz o trabalhador, tanto menos consegue possuir e tanto mais submetido fica à dominação de seu produto, quer dizer, do capital [...] tanto mais pobre se torna ele mesmo, seu mundo 
Assim como argumenta Marx (2004), parece-nos haver uma objetivação de Edgar Wilson em relação ao produto final do matadouro, de modo que ocorre o engrandecimento das mercadorias em oposição a degradação (desvalorização) dos seres humanos e dos animais não humanos. No Brasil, a indústria de processamento de carne é um grande mercado de trabalho, empregando mais de 1 milhão de trabalhadores, visto a enorme quantidade de animais abatidos e destinados ao consumo carnívoro. O Brasil possui, atualmente, o segundo maior rebanho bovino mundial, com cerca de 220 milhões de gados. Trata-se, enfim, de uma indústria duplamente cruel: com desrespeito à dignidade dos animais não humanos e marcada por uma estratégia de trabalho precarizado, com desrespeito às leis trabalhistas. Além de ser o local de trabalho em que mais ocorrem acidentes, deixando trabalhadores com diversos transtornos psicológicos e causando danos significativos ao meio ambiente, especialmente aos recursos hídricos (SILVA et al, 2012).

Edgar Wilson está imerso nessa crueldade, cuja "produção está se intensificando e será necessário contratar mais um atordoador" (MAIA, 2013, p. 20). Esse aumento efetivo da produção implica o aumento da precarização, pois Edgar Wilson terá sua força de trabalho explorada ainda mais, evidenciando-se, assim, que o narrador considera que a brutalidade desse personagem é fruto dessa exploração sem limites. Isto é, esse nexo implica, pois, não naturalizar a brutalidade, a indignidade da condição dos trabalhadores do matadouro.

Diante disso, é possível depreender interessantes reflexões. O primeiro aspecto, mais óbvio, é que o projeto literário de Ana Paula Maia problematiza uma modernização periférica que submete certa fração da classe trabalhadora a ocupações tão degradantes, sub-remuneradas e precárias que resultam em uma reprodução anômala da força de trabalho. O seu interesse por elaborar personagens que sejam "homensbestas" corresponde ao processo histórico-social do capital financeiro, cuja lógica

\footnotetext{
[...] se expressa com vigor na degradação do metabolismo social homemnatureza: seja a natureza humana expressa no cataclismo social, com seus milhões de trabalhadores precários e a massa de desempregados sem perspectivas de futuro digno e vítimas do adoecimento físico e mental; seja $a$ natureza natural com o cataclismo climático marcado pelo aquecimento global e deriva climática (ALVES, 2013, p. 29, grifos do autor).
}

Vê-se, pois, que a estrutura da composição do romance é formada de diversas cenas que buscam expor a ordem injusta da prevalência do capital financeiro, tendo a inserção do trabalho precarizado como ponto central da mediação estética do discurso narrativo. Como ponto central, ao longo do discurso narrativo, constrói-se um ponto de vista da classe trabalhadora precarizada que clarifica as implicações hegêmonicas do processo histórico-social de um país periférico como o Brasil ao ser integrado à mundialização do capital e ao neoliberalismo.

Todo o percurso de Edgar Wilson é marcado pela precarização do trabalho, porém, mesmo nessa negatividade, resta uma frágil esperança:

Quando a noite chegar, Edgar Wilson já estará em seu novo emprego, conhecendo os porcos e ouvindo seus grunhidos. Sabe que seus dias de predador continuarão, e que derramar sangue ainda será seu meio de sobrevivência. É o que sabe fazer. Talvez um dia encontre outro trabalho, um 
que seja limpo. Por enquanto, seguirá abatendo porcos; impuro e moralmente aceitável, é assim que ele se sente. Não há ninguém que o impeça, pois homens como ele são poucos, que são homens para matar. Os que comem são muitos e comem de modo que nunca se fartam (MAIA, 2013, p. 118-119).

Um trabalho limpo, com menos sujeira de espoliação e exploração, aos seus olhos, parece até um disparate na desigualdade em que está imerso, onde permanece desprovido de dignidade; ser "impuro", "bruto" não é uma deformação do personagem, - torna-se, isto sim, a principal possibilidade de sobreviver nessa realidade, sendo integrante da classe precarizada.

\section{Fraturas subjetivas de uma classe degradada}

O medo do desemprego e a esperança de possibilidades de ascensão social estão representados em ambos os romances. Almeja-se uma vida que não seja precarizada. Rosane, mais do que Edgar Wilson, é paradigmática da ideologia neoliberal segundo a qual a explicação corrente para o desemprego é atribuí-lo ao trabalhador, o qual deveria se responsabilizar por sua qualificação e "empregabilidade". A objetificação sob a forma-mercadoria e seus imperativos de produtividade ocasionaram em ambos os personagens modalidades de sofrimentos psíquicos. Diante do exposto, parece-nos que Rubens Figueiredo e Ana Paula Maia construíram Rosane e Edgar Wilson como figuras-tipo, no sentido exposto por Lukács (1978), para quem a tipicidade implica que as personagens e as circunstâncias sejam representativas da sociedade figurada na obra:

[...] por tipo, entendemos o compêndio concentrado daquelas qualidades que - por uma necessidade objetiva - derivam de uma posição concreta determinada na sociedade, sobretudo no processo de produção. [...] a criação de uma destas figuras típicas mesmo quando ela domina toda a obra (como frequentemente ocorre em Molière), por exemplo. É sempre apenas um meio para chegar ao fim artístico, que é o de representar a função deste tipo na ação recíproca de todos os contratipos que o contradizem como fenômeno típico de uma determinada etapa no desenvolvimento da humanidade (LUKÁCS, 1978, 263-64).

Rosane possui a ilusão de mobilidade social, de conquistar um trabalho não precarizado, de acordo com os cidadãos brasileiros de extratos inferiores que começaram a pensar em mobilidade social quando tiveram seu poder de consumo aumentado. Edgar Wilson é um personagem bruto, como brutalizada, objetificada e marginalizada é a classe que representa. Desse modo, não é exagero refletir que Edgar Wilson não é um perpetuador de violência, embora seja um "homem para matar"; na realidade, na medida em que vive em uma sociedade na qual "os que comem são muitos e comem de modo que nunca se fartam", torna-se vítima de uma violência social inaceitável do ponto de vista ético e político. "O surgimento da camada social do precariado é a prova histórica viva da falência da ordem social burguesa baseada nos ideais de emprego com direitos sociais, inclusão social com consumo e Estado social com democracia representativa", explica Alves (2013, p. 216).

Em ambos os romances, podemos notar um nexo de relação entre subjetividade e a precatização do trabalho; ao ser elaborado esse nexo, ao invés de ser uma mera redução cientificista naturalista, e o fato de os romances apontantarem para uma 
possibilidade de trabalho "limpo", isto é, não degradante, parece-nos possível depreender a função desfetichizadora da literatura, que ocorre, conforme argumenta Lukács (1968), quando o escritor não aceita o "estado de coisas existente":

\begin{abstract}
Insistimos, anteriormente, do ponto de vista da estética geral da literatura, sobre a posição central da figuração do homem. Podemos agora aduzir que esta representação constitui em, por força de sua própria lógica, um desmascaramento tão mais enérgico da desumanidade do capitalismo quanto mais esta inumanidade se explicita e generaliza no curso da crise geral do sistema capitalista. O escritor que figura homens reais pode ter apenas consciência parcial, ou ser inteiramente inconsciente, do fato de que a representação de homens reais em conflitos reais constitui já um princípio de revolta contra o sistema dominante (LUKÁCS, 1968, p. 91).
\end{abstract}

Dessa maneira e em face de nossa exposição precedente, parece-nos claramente que é, pois, contra o abafamento da cultura dos vencidos e dos oprimidos que a obra ficcional de Rubens Figueiredo e de Ana Paula Maia se insurge, podendo ser concebida como uma crítica social radical das ideologias da modernização do quadro institucional brasileiro (o papel econômico do Estado, inseparavelmente de seu conteúdo políticosocial) que permanecem iludidas pela regulamentação neoliberal.

\title{
5 Conclusões gerais
}

Rubens Figueiredo e Ana Paula Maia construíram, sem dúvida, romances ricos em diversos aspectos. Na textualização do discurso ficcional de Passageiro do fim do dia e de De gados e homens subjazem forças políticas e econômicas acerca de processos de mudanças sociais do Brasil contemporâneo. Buscou-se demonstrar que o realismo desses romances possibilita a concreção e eficácia da representação das dimensões social, psicológica e física de personagens submetidos à precarização do trabalho, tendo, em especial Edgar Wilson e Rosane, a mórbida visibilidade de formas de espoliação e opressão enquadradas em um regime de exploração do trabalho assalariado. Com base em reflexões nas áreas da sociologia do trabalho e da economia, argumentamos que os romances em questão representam uma fração específica da classe trabalhadora da contemporânea dinâmica socioeconômica brasileira, qual seja, o proletariado precarizado. Foi possível identificar também que, nos dois discursos narrativos, ambos os personagens estão inseridos em espaços periféricos marcados pelo "atraso" e pelo esquecimento, sendo lugares esvaziados de sentido quando contrastados com toda uma outra realidade, regida pelo progresso econômico e pelo mercado de consumo.

Dessa maneira, esperamos ter validado, na esteira dos estudos estéticos do filósofo húngaro Georg Lukács, que uma concepção materialista da forma literária contribui para verificar como a literatura brasileira contemporânea representa os problemas e as contradições ligadas à classe trabalhadora, permitindo verificar como há incorporação das contradições do capitalismo financeiro que assolam a dinâmica socioeconômica brasileira. Na construção deste artigo, foi proposto o recorte temático acerca das experiências de trabalho de Rosane e Edgar Wilson, focalizando e especificando a violência sistêmica do processo modernizador autoritário e desigual do Estado brasileiro, que fratura cotidianamente biografias a partir da imposição da precarização do trabalho. 


\section{REFERÊNCIAS}

ALVES, Giovanni. Dimensões da reestruturação produtiva: ensaios de sociologia do trabalho. 2. ed. Bauru: Canal 6, 2007.

Dimensões da precarização do trabalho: ensaios de sociologia do trabalho. Bauru: Canal 6, 2013.

ANTUNES, Ricardo. Adeus ao trabalho?: Ensaio sobre as metamorfoses e a centralidade do mundo do trabalho. 7. ed. São Paulo: Cortez; Campinas, SP: Editora da Universidade Estadual de Campinas, 2000.

BRAGA, Ruy. Memorabilia. In: A política do precariado: do populismo à hegemonia lulista. São Paulo: Boitempo, 2012, p. 13-36.

FIGUEIREDO, Rubens. Passageiro do fim do dia. São Paulo: Companhia das Letras, 2010.

Sobre Passageiro do fim do dia: entrevista com Rubens Figueiredo. Terceira Margem. Revista do Programa de Pós-Graduação em Ciência da Literatura UFRJ, Rio de Janeiro, n.24, p. 191-207, 2011.

GINZBURG, Jaime. O narrador na literatura brasileira contemporânea. Tintas. Quaderni di letterature iberiche e iberoamericane, Milano, n. 2, 2012, p. 199-221.

HARVEY, David. A transformação político-econômica do capitalismo do final do século XX. In: . Condição pós-moderna: uma pesquisa sobre as origens da mudança cultural. Tradução: Adail Sobral e Maria Stela Gonçalves. São Paulo: Loyola, 2008, p. 115-184.

JAMESON, Fredric. $O$ inconsciente político: a narrativa como ato socialmente simbólico. Tradução: Valter Lellis Siqueira. São Paulo: Ática, 1992.

LUKÁCS, Georg. Introdução a uma estética marxista. Tradução de Carlos Nelson Coutinho e Leandro Konder. Rio de Janeiro: Civilização Brasileira, 1978.

Narrar ou descrever? (contribuição para uma discussão sobre o naturalismo e o formalismo). Tradução de Giseh Vianna Konder. In: LUKÁCS, Georg. Ensaios sobre literatura. Rio de Janeiro: Editora Civilização Brasileira, 1965, p. 43-94.

Balzac: Les Illusions Perdues. Tradução de Luís Fernando Cardoso. In: LUKÁCS, Georg. Ensaios sobre literatura. Rio de Janeiro: Editora Civilização Brasileira, 1965, p. 95-114.

Marx e o problema da decadência ideológica. In:_. Marxismo e teoria da literatura. Tradução de Carlos Nelson Coutinho. Rio de Janeiro, Civilização Brasileira, 
1968, p. 49-111.

Romance como epopeia burguesa. In: COUTINHO, Carlos Nelson; NETTO, José Paulo (Orgs.). Arte e sociedade: escritos estéticos 1932-1967. Tradução de: Carlos Nelson Coutinho e José Paulo Netto. Rio de Janeiro: Ed. UFRJ, 2009, p. 191-243.

MAIA, Ana Paula. Entre rinhas de cachorros e porcos abatidos. Rio de Janeiro: Record, 2011.

De gados e homens. Rio de Janeiro: Record, 2013.

MARX, Karl. Salário, preço e lucro. In:

Os pensadores. Tradução: Edgard

Malagodi [et al.]. São Paulo: Abril Cultural, 1982.

Manuscritos econômico-filosóficos. Tradução: Jesus Ranieri. São Paulo: Boitempo, 2004.

PAULANI, Leda. Investimento e servidão financeira: o Brasil do último quarto de século. In: Brasil Delivery: servidão financeira e estado de emergência econômico. São Paulo: Boitempo, 2008, p.73-104.

RABELLO, Ivone Daré. Barco a seco, de Rubens Figueiredo: certezas e enganos da imagem identitária. Terceira Margem. Revista do Programa de Pós-Graduação em Ciência da Literatura UFRJ, Rio de Janeiro, v. 11, n. 16, p. 128-141, 2007.

SAFATLE, Vladimir. Fetichismo. Colonizar o Outro. Rio de Janeiro: Civilização Brasileira, 2010.

SILVA, Genival Nunes; MADI, Rubens Riscala; MELO, Cláudia Moura de; FONSECA, Vania. Matadouros públicos e saúde ambiental em Sergipe. Revista Saúde Social. 2012, vol. 21, n. 4, p. 1013-1021.

ŽIŽEK, Slavoj. Da dominação à exploração e à revolta. In: $O$ ano em que sonhamos perigosamente. Tradução: Rogério Bettoni. São Paulo: Boitempo, 2012, p. 16-34. 